\title{
Polícia que conversa: reciprocidade, publicidade e accountability na implantação da filosofia de polícia comunitária*
}

\begin{abstract}
RESUMO
O trabalho examina a mudança na comunicação pública da Polícia Militar de Minas Gerais sob a perspectiva da interlocução e da parceria decisória entre polícia e cidadãos, esperada com a implantação de uma filosofia de polícia comunitária. A instituição de instâncias formais de interação entre a PM e públicos locais - os Conselhos Comunitários de Segurança Pública - enseja uma atenção precípua aos princípios de reciprocidade, publicidade e accountability que devem presidir as condições de deliberação pública.
\end{abstract}

\section{PALAVRAS-CHAVE}

comunicação pública

deliberação

polícia comunitária

\section{ABSTRACT}

This article examines the change in the public communication of the Military Police of Minas Gerais under the perspective of dialogue and deliberation between police and citizens, face the introduction of community police practices. The constitution of formal interaction between PM and local publics - through community councils - brings an attention to the elements that should preside public deliberation conditions: reciprocity, publicity and accountability.

\section{KEY WORDS}

public communication

deliberation

community police

\section{Márcio Simeone Henriques}

Professor do departamento de Comunicação Social da UFMG/MG/BR simeone@fafich.ufmg.br
Desde o final da década passada a Polícia Militar de Minas Gerais iniciou, no âmbito do Comando de Policiamento da Capital, Belo Horizonte, o Plano de Polícia de Resultados. Instituído com o intuito de reduzir a criminalidade - que na década de 90 alcançara altíssimos níveis, baseia-se em dois eixos principais: o geoprocessamento e o policiamento comunitário. Este último corresponde a uma corrente doutrinária com raízes nas reformas policiais de muitos países, iniciadas há pelo menos três décadas. Além de uma simples alteração nas táticas cotidianas de policiamento, trata-se de uma filosofia, comumente descrita na literatura como uma mudança profunda na orientação e na missão policial, que deixa de ser reativa (com foco nos incidentes de caráter criminal) para ser preventiva e orientada para a solução de problemas (com foco na prevenção).

Tal característica informa que a polícia comunitária exige mudanças mais significativas no modelo das agências policiais, incluindo a sua cultura organizacional, de modo a torná-la mais aberta e permeável às demandas da população a que deve servir. Envolve participação dos cidadãos na própria gestão dos problemas de segurança que lhes concernem, sendo, por isso, um fator político considerável, condizente com a demanda por participação cívica nos negócios públicos, o que é próprio de democracias nos moldes deliberativos.

O caso da PMMG é particularmente interessante porque, além de redirecionar suas táticas de policiamento, começou progressivamente a institucionalizar a polícia comunitária como uma diretriz doutrinária. A implantação de instâncias formais de interlocução, os Conselhos Comunitários de Segurança Pública (CONSEP), em todo o Estado, cria uma nova configuração organizacional e demanda a administração de processos de interação completamente novos. Impõe o desafio de gerar e manter uma interlocução com o público - genericamente denominado de "comunidade" - e orientar suas ações em cada localidade por uma série de questões derivadas desse diálogo, que devem responder às expectativas geradas neste processo.

Este trabalho se ocupa desse aspecto da implantação da polícia comunitária: seu caráter deliberativo, que exige uma mudança nas políticas de comunicação da Polícia Militar. Acostumada a falar para a sociedade, agora é instada a conversar com as comunidades, o que representa uma transformação nada desprezível. O distanciamento entre a polícia e o público, sua estrutura burocrática rígida e hierárquica, sua pouca sensibilidade às demandas dos cidadãos e a resistência à interlocução e 
à parceria decisória, aos quais se junta um acúmulo histórico de casos de abuso do poder policial e desrespeito aos direitos humanos, tudo isso costuma lançar dúvidas sobre a viabilidade e a capacidade da instituição policial de implantar uma prática deliberativa. Examinaremos brevemente algumas questões que emergem com esta demanda pela conversa com os públicos locais e pelo estabelecimento de efetiva parceria decisória, a partir do exame do caso da PMMG, atentos aos princípios de reciprocidade, publicidade e accountability que regulam as condições para a ocorrência da deliberação pública.

\section{A filosofia de polícia comunitária: uma resposta política A princípio, a idéia de policiamento comunitário pode limitar-se a uma perspectiva operacional, onde a polícia busca exercer suas funções em proximidade maior com a população, usando de táticas de patrulhamento a pé (ou de bicicleta), em contraposição ao patrulhamento motorizado acionado por telefone (numa relação mais "fria" com o público). Mas diversos autores situam-na como uma filosofia, uma orientação distinta daquela que embasa o modelo reativo que se tornou hegemônico ao longo do século XX que previa um distanciamento da polícia por meio da profissionalização e burocratização de suas atividades. O modelo profissional enfatizaria a técnica e a eficiência operacional e, ao lado da burocrati- zação, buscaria garantir a neutralização das pressões cívicas do ponto de vista do regime administrativo e a neutralidade política e a confiabilidade legal da polícia, ao desenvolver um sistema hierárquico de comando e controle (Bordua; Reiss, 1966; Reiss Jr., 2003).}

\section{A implantação da filosofia de polícia comunitária no Brasil é consentânea com as mudanças no exercício político, com o processo de redemocratização das últimas décadas.}

A tentativa de estabelecer uma demarcação entre as atividades policiais e o exercício da política por meio deste modelo, além de promover a quebra de uma rede de relações entre a polícia localmente organizada e a comunidade a que servia (Goldstein, 2003), instaurou também uma tensão permanente entre a sua autonomia e a sua responsabilização, que se refletiu com bastante vigor na legitimidade da força policial em países democráticos (Moore, 2003). A partir da década de 1960, nos Estados Unidos, Grã-Bretanha e Canadá, seguidos de outros países, as novas configurações políticas e sociais instauram um movimento de "repolitização" da polícia, enquanto várias pesquisas começam a demonstrar o esgotamento do modelo de policiamento adotado quanto à efetividade na resolução de crimes e redução da violência nos grandes centros urbanos (Reiss Jr., 1971). Assim, ao lado de um questionamento sobre a eficácia das técnicas, a crise do modelo se fez acompanhar de um crescente questionamento sobre o papel das agências policiais em regimes democráticos, também muito influenciado pelas exigências de respeito aos direitos humanos.

Duas vertentes estratégicas importantes surgem como resposta ao desafio de gerar uma nova aceitação pública da polícia e reposicionar sua missão e operações, além de buscar maior efetividade na redução do crime: o policiamento orientado à solução de problemas e o policiamento comunitário (Goldstein, 2003). Ambas, na verdade, tornam-se complementares, intrinsecamente relacionadas, voltadas para as atividades de cunho preventivo - no lugar da ênfase dada às tarefas repressivas e envolvendo a direta participação do público (Peak \& Glensor, 2004; Moore, 2003). A proposta de polícia comunitária é movida pela idéia-força de que o público pode ser "coprodutor da segurança e da ordem, juntamente com a polícia" (Skolnick; Bayley, 2002, p.18). Em vários países, programas de policiamento comunitário e de solução de problemas começaram a ser experimentados desde a década de 1970, primeiro de forma isolada. Depois expandiram-se para várias partes do mundo, inseridos como doutrina, assumindo formatos diferenciados, mas tendo princípios em comum como a maior escuta (formal ou informal) da população, patrulhamento mais próximo e promoção de ações preventivas com a cooperação das comunidades.

A implantação da filosofia de polícia comunitária no Brasil é consentânea com as mudanças no exercício político, com o processo de redemocratização das últimas décadas. A Constituição Federal de 1988 criou condições para o exercício de uma cidadania que prevê interlocução entre poder público e sociedade civil, por meio de instâncias formais de interação que permitem a participação dos cidadãos nos negócios públicos, em especial na formulação de políticas públicas. Neste contexto, tomam forma diversos fóruns como os conselhos gestores de políticas públicas, cobrindo a grande variedade de áreas da administração pública, o que é reconhecido, em geral, como inovação institucional democrática (Avritzer, 1994, Fung, 2004a; Fung; Whright, 2001). A idéia de polícia comunitária está presente na PMMG desde a década de 1980, mas só ganhou força na década seguinte. A filosofia só ganharia fôlego para inserir-se realmente como doutrina e lograr maior efetividade a partir de 1999, com a implantação do "Plano de Polícia de Resultados", no âmbito do Comando de Policiamento da Capital (CPC) ${ }^{1}$. Baseava-se em dois eixos principais: mapeamento da criminalidade, através de técnicas de geoprocessamento, e atendimento descentralizado às 
demandas das comunidades através da criação de Conselhos Comunitários de Segurança Pública (CONSEP)².

\section{Mudança nos padrões de relacionamento: um desafio à comunicação pública da polícia}

A mudança nos padrões de relacionamento entre a polícia e os públicos sob a égide dos princípios de polícia comunitária e de resolução de problemas, torna-se uma questão complexa que necessita equacionar ambas as dimensões - operacional e política e tentar superar os principais obstáculos a uma proximidade com os públicos. A relação mais próxima com os públicos locais reflete a necessidade de resgatar a confiança na atuação da polícia, mas, além disso, através dessa confiança, obter a cooperação desses públicos na execução de suas tarefas. Jerome Skolnick e David Bayley colocam a escuta das demandas da população como condição para obtenção de apoio e cooperação para a participação civil no policiamento: "os policiais têm descoberto que, se desejam gozar do apoio e cooperação do público, devem estar preparados para ouvir o que a população tem a dizer, mesmo que seja desagradável" (Skolnick; Bayley, 2002, p.32). Isso implica em reciprocidade de comunicação que deve não somente ser aceita, mas encorajada

\section{Como observa Maia (2003), a publicidade, num sentido forte, não se limita a uma difusão ou exposição pública, mas também cria um espaço para a deliberação e o governa, produzindo padrões para julgar os acordos ali produzidos.}

O grau e a qualidade de participação que está em jogo sob este modelo é um ponto sempre controverso e conflitante, principalmente no que se refere à expectativa de deliberação conjunta dos atores que participam das instâncias formais. Entre as expectativas consultivas e deliberativas projetadas sobre estes fóruns, nem sempre há uma visão clara dos limites a partir dos quais a própria participação civil passa a ser considerada inconveniente pelas autoridades policiais. Sob este prisma, a implantação de polícia comunitária encontra vários obstáculos, principalmente no que se refere à cultura interna da corporação, que vão muito além da disposição de descentralização da autoridade, mudando a responsabilização interna do comando: a cultura fortemente cor- porativa, com forte solidariedade interna, cria dificuldades para aceitação do cidadão comum e de suas demandas; o sistema de recompensas, que tende a premiar mais os esforços de reação repressiva (pronta resposta), não incentiva o engajamento dos policiais em atividades tipicamente preventivas. Um dilema básico que preocupa a polícia é que a abertura à participação freqüentemente leva a uma maior pressão sobre a sua atividade e, com isso, ela tende a sentir maior cobrança em relação aos seus métodos de trabalho, aos resultados e ao próprio controle sobre as suas atividades mais rotineiras, que têm a ver com o seu poder discricionário (Goldstein, 2003).

Sob o ângulo externo, a expectativa de mudança no relacionamento com os públicos requer que a organização enfrente o desafio de lidar com uma imagem pública contraditória: por um lado pode inspirar admiração, confiança e sentimento de proteção (considerando a noção de uma função social cumprida pela polícia) e, por outro, o medo, a suspeita e a desconfiança (considerando a polícia como símbolo de autoridade e força e mesmo devido ao acúmulo histórico de abusos do poder policial). Essa ambigüidade nas expectativas sociais em relação ao papel da polícia e, conseqüentemente, na sua imagem perante a população constitui um problema delicado, que demarca os limites dentro dos quais o relacionamento com os públicos tem lugar. A cultura organizacional fortemente marcada estimula percepções coletivas contraditórias (Punch, 1979), ou mesmo repleta de estigmas que recaem sobre a figura do policial e sobre as suas tarefas (Bittner, 1975).

Quanto à comunicação organizacional, o desafio, ao introduzir a filosofia de polícia comunitária, é o de traçar uma política de comunicação pública que contemple essa nova demanda. Seja do ponto de vista das estratégias de comunicação interna, seja com mudanças na maneira como se refere aos públicos externos. Para estes, cremos que o modelo tradicional de relações públicas, baseado essencialmente na difusão de informações para públicos gerais em larga escala, não se mostra mais adequado e suficiente para atender à demanda de estabelecer contatos mais próximos com públicos específicos. De uma ênfase quase exclusiva na produção e difusão de informações, passa-se à exigência de interlocução, o que altera o fluxo comunicativo. Ao lado das funções já tradicionais de esclarecer sobre as questões públicas e prestar contas, deve voltar-se também para a função de estabelecer políticas e estratégias de comunicação que estimulem a participação e cooperação dos cidadãos, estabeleçam e orientem a interlocução e fomentem o debate cívico (Zémor, 1995), ou seja, deve abranger as relações comunicativas que tem por objeto a deliberação conjunta entre a polícia e os cidadãos.

Por deliberação entendemos não apenas tomadas de decisão formais do sistema político ou o debate que as precede, mas um processo argumentativo bem mais amplo e dialógico de troca de razões, de discussão em 
público que busca, pela coordenação e cooperação entre os sujeitos envolvidos, entender e/ ou resolver situaçõesproblema que escapam às suas esferas individuais (Bohman, 2000; Dryzek, 2004). A expectativa é de que a deliberação seja um processo contínuo, dinâmico, que mantenha abertura ao diálogo cooperativo. Supõe disposição constante para a discussão de atores muito diversificados, o acolhimento das divergências e a expectativa de algum entendimento mútuo. Para isso, os públicos devem ter possibilidade não apenas de participar dos fóruns, mas de apresentar seus argumentos e suas propostas sobre os temas em debate, livres de constrangimentos, coerções, recompensas e sanções (Bohman, 2000).

\section{A falta de uma visão mais uniforme sobre as expectativas de contribuição dos participantes civis também é recorrente.}

Também são pertinentes preocupações com as condições essenciais para que nestes fóruns se efetive uma deliberação democrática e, conseqüentemente, com os princípios que regulam essas condições: reciprocidade, publicidade e accountability (Guttman; Thompson, 1996). Isso evidencia que a prática da deliberação pública não exige apenas atenção a processos comunicativos que ocorrem para divulgar ou chamar à participação, mas também quanto às possibilidades de propor publicamente a tematização de questões que devem ser reconhecidas como relevantes. Como observa Maia (2003), a publicidade, num sentido forte, não se limita a uma difusão ou exposição pública, mas também cria um espaço para a deliberação e o governa, produzindo padrões para julgar os acordos ali produzidos. O posicionamento dessas questões no plano coletivo envolve negociação de sentidos onde entram em jogo interesses individuais, formulação de acordos através do debate público e a promoção de sua visibilidade. Os fóruns de discussão abertos à participação dos cidadãos precisam operar sob exposição pública de razões, tanto no sentido de que possam ser livremente expressas, como também de serem reconhecidas como válidas. Por outro lado, a discussão - e a eventual tomada de decisões informada sobre os assuntos públicos - depende, como condição geral, da disponibilidade aberta de informações (Bohman, 2000; Held, 1995), que devem ser inteligíveis para o público e de uma oferta ao conhecimento público dos fenômenos, intenções, planos e atualidades. As condições e princípios criam, portanto, um nexo fundamental com a prática da comunicação institucional, seja dos próprios fóruns, seja das agências administrativas do poder público que a ele estão ligados.

\section{0 problema da deliberação através dos Conselhos Comunitários de Segurança Pública}

Ao mesmo tempo em que um modelo de democracia deliberativa cria oportunidades de participação dos cidadãos em processos de formulação e controle de políticas públicas, traz o desafio de garantir a qualidade e a legitimidade dessas deliberações, principalmente em larga escala (Dryzek, 2004). Por outra via, também é importante considerar as possibilidades efetivas de engajamento cívico e deliberação através de mecanismos de menor escala. Os CONSEP assemelham-se ao tipo que Archon Fung (2004a) denomina de "minipúblicos", ou seja, não configuram uma instância de deliberação em larga escala, mas em escala reduzida e localizada. O autor analisa pelo menos oito desenhos institucionais diferentes para este tipo de deliberação, dentre eles um tipo que denomina de "cooperação para a resolução participativa de problemas", que prevê "um relacionamento contínuo e simbiótico entre o Estado e a esfera pública destinado a solucionar determinados problemas coletivos" (Fung, 2004a, p.177). Diversas questões acerca da deliberação nesta escala e sobre os mecanismos capazes de impulsionar a participação e a mobilização dos atores locais se apresentam como relevantes. De modo mais específico, a chamada à parceria decisória na área de segurança envolve alguns dilemas comumente enfrentados nos processos deliberativos.

Destacamos neste trabalho alguns desses dilemas, vistos sob a perspectiva específica da constituição dos Conselhos Comunitários de Segurança Pública, na ótica de alguns de seus protagonistas. Os dados foram coletados através de pesquisa de campo em amostra de três CONSEP da cidade de Belo Horizonte, com características diferentes. Ao lado de entrevistas em profundidade com os membros desses Conselhos e com os comandantes das respectivas Companhias PM, foram também realizadas entrevistas com oficiais do Estado-Maior da PMMG diretamente envolvidos na concepção e implantação do Plano de Polícia de Resultados e/ou em situação atual de comando em postos-chave do emprego operacional da $\mathrm{PM}^{3}$. O exame desses dilemas em relação aos princípios diretores das condições de deliberação - reciprocidade, publicidade e accountability - pode evidenciar pontos críticos que merecem atenção para o desenvolvimento das políticas organizacionais da Corporação, mais especialmente para o delineamento de uma política de comunicação pública.

(a) Reciprocidade - O problema de estabelecer o alcance deliberativo dos CONSEP é ponto capital na definição de sua forma de atuação. Os princípios inscritos na diretriz que orienta a polícia comunitária na PMMG deixam clara a expectativa de que haja condições efetivas de parceria decisória para resolução de problemas de segurança: "estabelecimento de um estilo de processo decisório baseado em estreita parceria dos órgãos da segurança pública com a comunidade" (Minas Gerais, 
2002, p. 3). Esta expectativa mostra-se bem clara por parte de oficiais do Estado-Maior:

O ideal é que o CONSEP seja a instância onde a comunidade possa apresentar os seus problemas e possa conjuntamente resolver. Em algumas localidades não terá o poder de deliberar, mas essa deliberação existe e ocorre. As pessoas têm um poder de fato na mão de ajudar a encaminhar o serviço e assumir compromissos. Muitas vezes, a resposta e a solução para um problema local estão nas mãos da própria comunidade, mais do que nas da polícia. Para estas questões ela acaba tomando decisões e se comprometendo com ela, encaminhando a outros órgãos etc. (Oficial, Estado-Maior).

Porém, a força de deliberação desses conselhos é algo, além de delicado, controverso e dependente da compreensão de todos os níveis hierárquicos. É evidente a dificuldade da polícia de orientar-se por compromissos gerados nessa instância. O problema da reciprocidade na relação entre polícia e públicos manifesta-se costumeiramente vinculado à necessidade de mudança da cultura interna e de preparo dos policiais para lidar com a comunidade:

Não tem poder deliberativo, porque temos problemas sérios na cultura da própria instituição (Oficial, Estado-Maior).

Tem que estar preparado para isso, para atender bem a comunidade. [...] Alguns policiais mais antigos não entendem isso e acham que não pode 'um paisano mandar em mim'. A própria formação nossa, de antigamente, não permite isso (Oficial, Comandante de Cia.).

A falta de uma visão mais uniforme sobre as expectativas de contribuição dos participantes civis também é recorrente. Às vezes, a participação pode ser meramente "passiva" (presença em palestras ou em eventos promovidos pela PM ou pelo CONSEP ou mesmo participação específica em projeto desenvolvido com a participação da PM). Na perspectiva de uma cooperação mais "ativa", as expectativas mais comuns são de que a comunidade colabore com denúncias, participe de esquemas colaborativos de prevenção (como as redes de vizinhos protegidos), auxilie na reocupação de espaços públicos, forneça apoio logístico (ou mesmo patrocínio). Muitas vezes, o histórico de parcerias logísticas é indicador de boas relações com a PM, mas os oficiais da PM criticam, em geral, as experiências que se limitam apenas a uma ênfase nas parcerias logísticas ou trabalhos assistenciais:

Há um desvirtuamento do que seria polícia comunitária em cima de uma visão equivocada de parce- ria, uma parceria que acaba sendo logística: doar viaturas, prover equipamentos que o Estado não fornecia. [...] Com isso a população não se coloca na posição de participar efetivamente, mas acha que ao doar já está participando e pode cobrar maior eficiência (Oficial, Estado-Maior).

A questão do alcance deliberativo mostra-se imprecisa (qual o tipo de participação, sobre o quê se deve realmente deliberar, até que ponto a comunidade pode ou não interferir nas práticas e operações policiais, em que medida as partes selam compromissos em relação às ações de prevenção). De outra via, a configuração sugerida para o CONSEP, de uma associação civil, prevê algum tipo de deliberação interna, para decidir sua forma de atuação independentemente da tutela da polícia. O que gera também uma série de problemas, principalmente quanto às possibilidades de participação do cidadão comum, que não seja associado:

\section{Considera-se fundamental a prestação de informações qualificadas que orientem melhor 0 cidadão sobre as possibilidades de participação, principalmente em comparação com outras áreas do poder público.}

Vou chamar o cidadão para participar das reuniões. Mas na hora de deliberar, como é o processo de deliberação? Só para quem é filiado. Como é o processo de filiação? Aí os CONSEP começam, nos seus regimentos internos a limitar a possibilidade de a pessoa votar à participação em determinado número de reuniões. Além disso, as pessoas que vão votar tem que ter algum peso dentro da comunidade (Oficial, Estado-Maior).

Isso chama a atenção para os constrangimentos à participação do cidadão comum nos debates, reforçando o caráter mais institucional das representações nos CONSEP4. Mas há outras situações que também limitam a representatividade e a reciprocidade esperada: as resistências históricas ao próprio contato com a polícia e os constrangimentos à participação de instituições de certas localidades. Um dos grandes desafios é o da participação de lideranças dos aglomerados (vilas, favelas), 
principalmente aqueles que são considerados áreas de risco, dada sua vulnerabilidade às situações de violência. Em vários dos CONSEP não houve envolvimento dessas lideranças ou, em alguns casos, a participação é sempre encarada com cautela e com reservas pelos próprios líderes:

A gente encontra com as lideranças [dos aglomerados], conversa, telefona. Mas o lugar onde eles mais gostam de conversar com a gente é quando a gente encontra na Prefeitura, quando tem OP [Orçamento Participativo] ou outro encontro (Membro de CONSEP).

Eles [os líderes dos aglomerados] não participam, porque sentem que não é bom mexer com isso, tem muito risco, então eles atuam de outra forma, vão conversando com a gente, mas não nas reuniões com a polícia militar. Eles ficam preocupados porque moram num lugar que tem alguma violência, apesar de ter melhorado. Eles ficam com medo de ter esse contato com a polícia (Presidente de CONSEP).

Alguns [líderes dos aglomerados] participam mais discretamente, porque tem receio. Mas a gente tem ido muito a essas comunidades, nas associações deles, pra discutir sobre as questões da segurança (Presidente de CONSEP).

Também emerge neste contexto a dependência desses conselhos da atuação da Polícia Militar, o que se reflete numa restrição do espaço de decisão mais autônoma:

Eu acho que não há uma expectativa deliberativa mais forte, organizando pautas e projetos, estabelecendo prioridades, por conta da própria organização dos conselhos, que dependeram muito da iniciativa da polícia para se constituir (Oficial, Estado-Maior).

(b) Publicidade - Há uma percepção comum aos entrevistados de que a população de modo geral, não conhece os CONSEP nem identifica a filosofia de polícia comunitária e que a falta de divulgação, seja mais ampla, seja no nível das localidades, é uma das razões para o desconhecimento e para a baixa participação:

A população conhece o Consep? Acredito que na sua maioria, não. Acho que falta um trabalho para, primeiro, a gente conscientizar as lideranças (Oficial, Comandante de Cia).

A comunidade não participa; a gente não divulga o CONSEP (Presidente de CONSEP).

Na realidade a maioria da população da região não sabe o que é o CONSEP, porque não tem interesse. As pessoas se fecham. Há os que ficam surpresos se ficarem sabendo. A maioria não preocupa em interagir. Muitos nem conhecem as associações do bairro. Muitos não sabem que tem um pelotão da PM no bairro (Oficial, Comandante de Cia.).

Considera-se também fundamental a prestação de informações qualificadas que orientem melhor o cidadão sobre as possibilidades de participação, principalmente em comparação com outras áreas do poder público:

Seria utopia da parte da PM imaginar que todo cidadão ordeiro compreendesse ou estivesse disponível para compreender o que é polícia comunitária e que ele pode ter voz ativa no processo. [...] Ainda carecemos de muita informação qualificada, de muita informação de mídia mesmo, no sentido de divulgar o que é polícia comunitária (Oficial, Estado-Maior).

Os CONSEP da amostra utilizam poucos instrumentos de divulgação, além da comunicação interpessoal. Há uma percepção de que as formas de divulgação não são suficientes para chamar à participação, mas isso sugere também que não se dá muita visibilidade às questões que são discutidas e sobre as deliberações desses conselhos:

A divulgação é mais boca-a-boca (sic) ou faixas, por exemplo. Mas, infelizmente, mobilizar o povo é difícil. [...] Também falava nas igrejas e a gente panfletava nos condomínios (Oficial, Comandante de Cia.).

(c) Accountability - As reuniões dos CONSEP envolvem, em regra, a apresentação pelo Comandante da Companhia dos dados estatísticos extraídos do geoprocessamento, o que figura como importante ponto de pauta, em geral para iniciar as discussões:

Geralmente a gente passa a estatística criminal da Companhia, da área toda, a gente comenta essa estatística, quais são os crimes que mais aconteceram, qual foi a resposta da polícia, a gente faz um comparativo deste ano com o ano passado (Oficial, Comandante de Cia).

A polícia traz as informações, inclusive através de mapeamento: os locais, as fotos dos criminosos, ela tá sempre informando pro pessoal o trabalho que ela tem prestado, mostra os dados todos dos mapas (Presidente de CONSEP).

Mesmo com força deliberativa limitada, os encontros demonstram que uma dimensão de prestação de contas da polícia está de certo modo presente e que essa accoun- 
tability é fator apreciável, de ambos os lados, criando um fluxo de informações que, de outra forma, não aconteceria:

A coisa mais louvável da PM é trazer ao conhecimento da população o geoprocessamento (Presidente de CONSEP).

O ponto mais forte do CONSEP, no meu ponto de vista era a cobrança deles sobre o que a Polícia tá fazendo, uma prestação de contas: trabalhei assim e assim, tive tal dificuldade, tal resultado; acho que é uma coisa muito importante e talvez se existisse só pra isso já valeria a pena (Oficial, Comandante de Cia.).

De toda forma isso garante que a PM possa ouvir a comunidade e uma aproximação maior e serve para a PM saber que se não estiver atendendo à demanda da comunidade não adianta. [...] Os líderes comunitários começam a identificar isso mudar as referências que tem de polícia e do conceito operacional de polícia (Oficial, Comandante de Cia.).

De todo modo, evidencia-se a indissociabilidade dos três princípios, já que as restrições e limitações em qualquer um deles comprometem a efetividade dos demais. Isso também ressalta a importância de compreender a lógica comunicativa implicada neste processo, que não pode, de forma alguma, conformar-se apenas ao princípio da publicidade.

\section{Considerações Finais}

Com o estudo realizado, podemos perceber que, apesar da expectativa de parceria decisória, os CONSEP enfrentam várias dificuldades para constituírem-se como instâncias deliberativas, no sentido de fóruns abertos, tais como as restrições à participação do cidadão comum, participação inibida de certos segmentos, falta de preparo dos policiais para lidar com situações deliberativas, mas, principalmente, a falta de clareza sobre limites e alcance das deliberações, o que, de certo modo, compromete o princípio de reciprocidade que deve guiar o processo deliberativo. Além disso, há variadas expectativas de participação da comunidade, sem uniformidade de visão sobre o tipo de contribuição dos públicos locais. Os CONSEP e as companhias às quais estão ligados utilizam poucos recursos de divulgação e possuem recursos limitados em termos de instrumentos de comunicação dirigida, o que é visto como problema para atingir um nível satisfatório de mobilização das comunidades e dar visibilidade pública para o que se discute e delibera nos conselhos. No entanto, vistos os próprios CONSEP como estratégia de comunicação, são instâncias onde se realiza accountability em certa medida. Mesmo assim, pode-se questionar a limitação dessa prestação de contas, já que, de modo mais abrangente, uma accoun- tability mais efetiva carece de um razoável grau de reciprocidade e de publicidade.

Acentuam-se, assim, os desafios de traçar estratégias de comunicação pública que possam dar suporte a todo esse conjunto de relações de proximidade - com os cidadãos nas localidades e com as diversas instituições com as quais a Polícia precisa manter interlocução. Neste mapa de relacionamentos - uma "comunidade" composta por variados grupos de cidadãos e instituições com seus diversos graus de representatividade e legitimidade - enseja relações (todo o tempo) contraditórias, divididas entre o conflito e a cooperação, o que é próprio de um jogo de relações políticas e deve ser encarado como o desafio da participação em modelos democráticos de deliberação pública. A comunicação pública para esta finalidade precisa ser aberta o suficiente para não só informar cidadãos e instituições sobre as possibilidades de deliberação, mas também para buscar manter coesão entre os diversos atores, não obstante as suas diferenças. A tarefa é a de garantir a manutenção da instância de interlocução, da forma mais representativa, legítima e estável possível mfamecos

\section{NOTAS}

* Trabalho apresentado ao Grupo de Trabalho "Comunicação e Política", do XVII Encontro da Compós, na UNIP, São Paulo, SP, em junho de 2008. O artigo baseia-se em pesquisa realizada para fins de doutoramento em Comunicação pela Universidade Federal de Minas Gerais.

1. Concebido e iniciado em 1999 , foi institucionalizado como diretriz operacional mais tarde, em 2002, quando os elementos do Plano de Polícia de Resultados passam a ter status de doutrina, regulando o emprego da PMMG na segurança pública. É um marco para a generalização do modelo para além da Capital.

2. No ano 2000 o programa alcançou maior dimensão com a implantação simultânea de 25 CONSEP por iniciativa da PMMG, no âmbito territorial de cada uma das 25 companhias do município de Belo Horizonte.

3. Foram realizadas ao todo 22 entrevistas individuais, com roteiro semi-estruturado, sendo 11 com oficiais PM e 11 com lideranças comunitárias civis, no período de março de 2006 asetembro de 2007.

4. No caso dos conselhos de Belo Horizonte, o que se verifica é uma representação majoritária de lideranças das associações de bairro.

\section{REFERÊNCIAS}

AVRITZER, Leonardo. Sociedade Civil e Democratização. 
Belo Horizonte: Del Rey, 1994.

BITTNER, Egon. The functions of the police in modern society. New York: Jason Aronson, 1975.

BOHMAN, James. Public Deliberation: Pluralism, complexity and democracy. Massachusetts/USA: MIT

Press, 2000.

BORDUA, David J.; REISS Jr., Albert J. Command, control, and charisma: Reflections on police

bureaucracy. The American Journal of Sociology, 72(1), 1966. p. 68-76.

DRYZEK, John S. Legitimidade e economia na democracia deliberativa. In: COELHO, Vera S. P.; NOBRE,

Marcos. Participação e deliberação: Teoria democrática e experiências institucionais no Brasil contemporâneo. São Paulo, Editora 34, 2004. p. 41-62.

FUNG, Archon. Receitas para esferas públicas: oito desenhos institucionais e suas conseqüências. In: COELHO, Vera S. P.; NOBRE, Marcos. Participação e Deliberação: Teoria democrática e experiências institucionais no Brasil contemporâneo. São Paulo: Ed. 34, 2004a. p. 173-209.

FUNG, Archon. Empowered Participation: Reinventing Urban Democracy. Princeton Univ. Press, 2004b.

FUNG, Archon; WRIGHT, Erik O. Deepening Democracy: Innovations in Empowered Participatory Governance. Politics $\mathcal{E}$ Society. 29(1), 2001. p. 5-41.

GOLDSTEIN, Herman. Policiando uma sociedade livre. São Paulo: Editora da Universidade de São Paulo, 2003.

GUTMANN, Amy; THOMPSON, Dennis. Democracy and Disagreement. Cambridge, MA: Harvard

University Press, 1996.

HELD, David. Democracy and the Global Order: from the modern state to cosmopolitan governance.

Cambridge: Polity Press, 1995.

MAIA, Rousiley C. M. Dos dilemas da visibilidade midiática para a deliberação pública. LEMOS, André et al. (orgs.). Livro da XII Compós. Porto Alegre: Sulina, 2004. p. 9-38.

MINAS GERAIS. Polícia Militar. Diretriz para a produção de serviços de segurança pública n. ${ }^{\circ}$ 04/2002 CG: A Filo- sofia de Polícia Comunitária na Polícia Militar de Minas Gerais. Belo Horizonte: Comando-Geral daPMMG, 2002.

MOORE, Mark H. Policiamento Comunitário e Policiamento para a Solução de Problemas. In:TONRY, Michael; MORRIS, Norval (orgs.). Policiamento Moderno. São Paulo: Editora da Universidade de São Paulo, 2003. p. 115-175.

PEAK, Kenneth J.; GLENSOR, Ronald W. Community Policing and Problem Solving: Strategies andPractices. 4.ed. New Jersey, EUA: Prentice Hall, 2004.

PUNCH, Maurice. The secret social service in the British Police. London: Edward Arnold Publishers, 1979.

REISS Jr., Albert J. The police and the public. New Haven/ London: Yale University Press, 1971.

REISS Jr., Albert J. Organização da Polícia no Século XX. In: TONRY, Michael; MORRIS, Norval (orgs.). Policiamento Moderno. São Paulo: Editora da Universidade de São Paulo, 2003. p. 65-114.

SKOLNICK, Jerome H.; BAYLEY, David H. Policiamento comunitário. Questões e práticas através do mundo. São Paulo: Editora da Universidade de São Paulo, 2002.

ZÉMOR, Pierre. La Communication Publique. PUF, Col. Que sais-je? Paris, 1995. 